\title{
Changes in bone mass during low dose corticosteroid treatment in patients with polymyalgia rheumatica: a double blind, prospective comparison between prednisolone and deflazacort
}

\author{
Michael R Krogsgaard, Gorm Thamsborg, Birger Lund
}

\begin{abstract}
Objective-To compare the long term effects of low dosage prednisolone or deflazacort treatments on bone mass in patients with polymyalgia rheumatica. Methods-Thirty patients with polymyalgia rheumatica were allocated on a random double blind basis to receive treatment with prednisolone or deflazacort. Bone mineral content (BMC) was measured in the lumbar spine and in the distal forearm before treatment and three, six, and 12 months after treatment.

Results-At three months the decrease in lumbar BMC and bone mineral density (BMD) was significantly greater in the deflazacort group than in the prednisolone group $(p<0.05)$, but at six and 12 months there was no difference between the two groups. In all patients after one year there was a significant loss of BMC: a $6.4 \%$ loss in lumbar BMC and a $\mathbf{1 . 8 \%}$ loss in distal forearm BMC. Loss in lumbar BMC after six months was correlated to the cumulative dose of corticosteroid $(r=0.4$; $p<0.05)$ and was significantly greater in the group of patients who had persisting symptoms of polymyalgia at six weeks, three months, or both, after treatment started $(p=0.05)$.

Conclusion-This low dose study failed to reveal any calcium sparing properties of deflazacort compared with prednisolone. Possible explanations for this finding are discussed.
\end{abstract}

(Ann Rheum Dis 1996; 55: 143-146)

Since the early 1950s, osteopenia has been recognised as a complication of treatment with exogenous corticosteroids. ${ }^{1-4}$ The bone loss has been found to be considerable in patients treated with large doses of corticosteroids, ${ }^{5}$ but it has been proposed that low dosage corticosteroid treatment ${ }^{6}$ does not induce bone loss and may even be beneficial for bone mass in patients with rheumatoid arthritis, as it increases patient activity by reducing disease activity. It has been shown that deflazacort, a synthetic derivative of prednisolone, has less effect on bone mass compared with pred- nisolone in dose ratios of $6 \mathrm{mg}$ deflazacort to 5 mg prednisolone..$^{7}$

The present study aimed to compare the long term effects on bone mass of corticosteroid treatment with prednisolone and deflazacort, in patients with polymyalgia rheumatica, which has not previously been described.

\section{Patients and methods}

PATIENTS

Consecutive patients who had polymyalgia rheumatica diagnosed according to the criteria recommended by Bird $^{8}$ were asked to participate in the study. Patients with neoplastic diseases, kidney or liver disease, temporal arteritis or other rheumatic diseases, malabsorption, bone diseases (for example, Paget's disease), or a history of medication with fenytoin or systemic corticosteroids were excluded. Patients treated with oestrogens or androgens for more than six months during the past 10 years were excluded also.

\section{METHODS}

Bone mineral content was measured before corticosteroid treatment and three, six, and 12 months after the treatment started.

Bone mineral content in the lumbar vertebral bodies of $\mathrm{L} 2,3$, and 4 (L-BMC) was measured with dual photon absorptiometry, using BMC-Lab 22a from Novo Diagnostic Systems with a gadolinium-153 source. The coefficient of variation for this method is $4.5 \%$. Bone mineral content in the forearm (A-BMC) was measured with single photon absorptiometry, using a Novo GT 35 from Novo Diagnostic Systems with an iodine-125 source. A-BMC was measured in the area $8-24 \mathrm{~mm}$ proximal to the position at which the radius and ulna are seen as two separate bones. The coefficient of variation of the technique was $2 \cdot 2 \%$.

The patients were treated initially with either prednisolone $20 \mathrm{mg} /$ day or deflazacort $24 \mathrm{mg} /$ day, given double blind in tablets of 5 and $6 \mathrm{mg}$, respectively. After the first six weeks, the dose was changed according to disease activity during ambulatory control every second to fourth week. Attempts were continually made to find the smallest dose of 
corticosteroid that kept the disease under clinical and biochemical control. During the first six weeks it was necessary to increase the dosage to more than four tablets/day in four patients because of unsatisfactory disease control. These patients received 188, 220, 296, and 308 tablets, respectively, during the first six weeks, compared with 168 tablets received by other patients. When the prescribing code was broken, all four were found to have been treated with deflazacort.

Assessment of the clinical disease activity included grading of proximal muscle pain, proximal muscle tenderness, and morning stiffness on a scale from 0 to 3 . All patients were seen and graded by the same doctor. Biochemical measurements included erythrocyte sedimentation rate and fibrinogen concentrations.

The study was approved by the local ethics committee, and the patients received written and oral information in accordance with the Helsinki declaration.

\section{STATISTICAL ANALYSIS}

Paired data were compared using Wilcoxon's rank sum test and unpaired data were compared with the Mann-Whitney test. Changes in BMC over time were tested by Friedman's and Page's tests. Correlations were tested with Spearman's test. A value of $p=5 \%$ was considered significant.

\section{Results}

Thirty patients entered the study; 14 received deflazacort and 16 received prednisolone. The table lists their details.

Three patients died during the first year of treatment. The causes of death were pulmonary embolism (after six weeks), Listeria meningitis (after six months), and retroperitoneal tumour (of unclassified type) (after three months), respectively. The data obtained from these three patients were not included in the statistical analysis. One patient was able to stop treatment after five months without relapse; his 0-3 month BMC values were included in the analysis. One patient was admitted to another hospital after eight months, and his treatment was continued as prednisolone; subsequent breaking of the original prescribing code revealed that he had previously been taking deflazacort. His 0-6 month BMC values were included in the

Clinical characteristics of 30 patients treated with either deflazacort or prednisolone for polymyalgia rheumatica

\begin{tabular}{lll}
\hline Variable & $\begin{array}{l}\text { Deflazacort } \\
(n=14)\end{array}$ & $\begin{array}{l}\text { Prednisolone } \\
(n=16)\end{array}$ \\
\hline Sex (F/M) & $10 / 4$ & $9 / 7$ \\
Age (years) & $75.0(68$ to 83$)$ & $72.5(68$ to 83$)$ \\
ESR (mm/1st h) & $63(52$ to 76$)$ & $75(42$ to 95$)$ \\
Fibrinogen (nmol/l) & $15.6(15.0$ to 20.0$)$ & $15.9(13.5$ to 23.2$)$ \\
Muscle pain & $3(3$ to 1$)$ & $3(3$ to 1$)$ \\
Muscle tenderness & $2(3$ to 1$)$ & $2(3$ to 1$)$ \\
Morning stiffness & $3(3$ to 1$)$ & $3(3$ to 1$)$ \\
\hline
\end{tabular}

Values are medians ( $95 \%$ confidence limits).

Muscle pain, muscle tenderness and morning stiffness expressed on a scale of 0 (=no symptoms) to 3 .

ESR = Erythrocyte sedimentation rate. analysis. All other patients accomplished 12 months of treatment.

There was no difference between the groups in disease activity before treatment, when measured as the summed scores for muscle pain, muscle tenderness, and morning stiffness for each patient (median summed score of 8 in the prednisolone group and 7 in the deflazacort group). The clinical and biochemical parameters normalised rapidly for most patients in both treatment groups. Muscle pain was significantly stronger in the deflazacort group at six weeks and three months $(p<0.05)$, but there was no other difference between the groups. The median doses of corticosteroid at three, six, and 12 months were deflazacort $19.5 \mathrm{mg}$ ( $95 \%$ confidence limits (CL) 12 to $24 \mathrm{mg}$ ), $15 \mathrm{mg}$ (95\% CL 6 to $18 \mathrm{mg}$ ), and $12 \mathrm{mg}$ (95\% CL 6 to $24 \mathrm{mg}$ ), respectively; values for prednisolone were $12.5 \mathrm{mg}$ (95\% CL 10 to $15 \mathrm{mg}$ ), $10 \mathrm{mg}$ ( $95 \% \mathrm{CL} 7 \cdot 5$ to $15 \mathrm{mg}$ ), and $7.5 \mathrm{mg}$ (95\% CL 2.5 to $12.5 \mathrm{mg}$ ), respectively.

Figures 1 and 2 show the changes in L-BMC and A-BMC, respectively, during the first year of treatment. A-BMC was calculated as the average of both arms for each patient. The median L-BMD before corticosteroid treatment was $0.773 \mathrm{~g} / \mathrm{cm}^{2}$ (95\% CL 0.673 to 0.906 ) in the deflazacort group and $0.832 \mathrm{~g} / \mathrm{cm}^{2}$

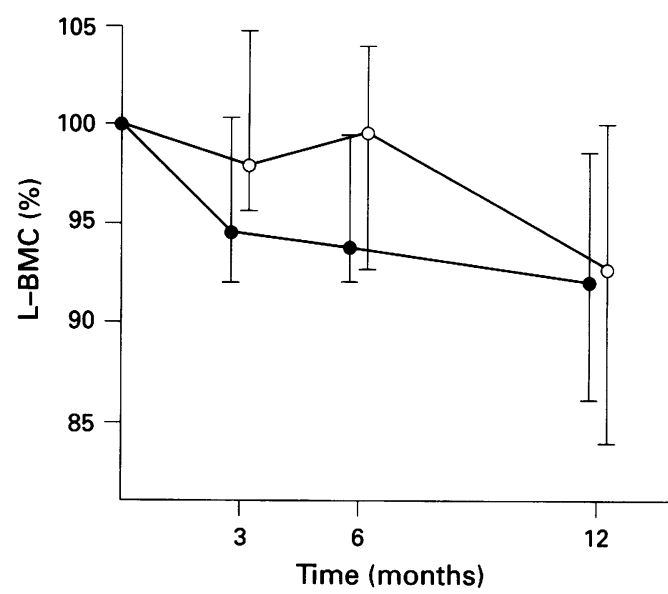

Figure 1 Changes in lumbar bone mineral content ( $L-B M C)$ (median with 95\% confidence intervals) after three, six, and 12 months treatment with low dose deflazacort ( ) or prednisolone $(\mathrm{O})$ in patients with polymyalgia rheumatica.

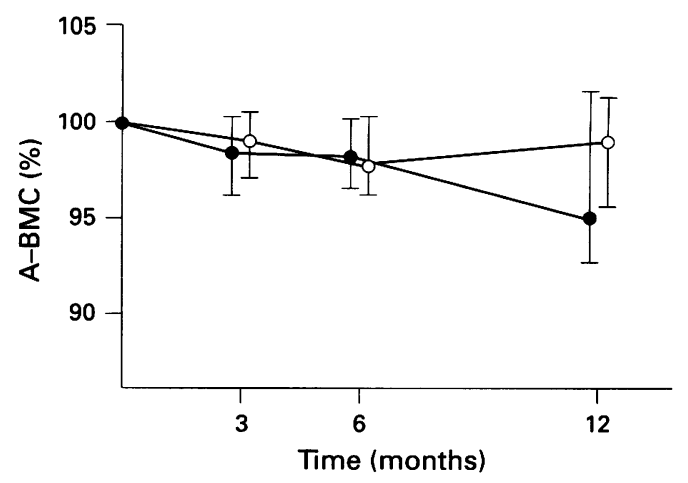

Figure 2 Changes in forearm bone mineral content ( $A-B M C)$ (average of both arms) (median with 95\% confidence intervals) three, six, and 12 months after treatment with deflazacort $(\bigcup)$ or prednisolone $(O)$ in patients with polymyalgia rheumatica. 
(95\% CL 0.746 to 0.949 ) in the prednisolone group (difference not significant).

L-BMC decreased in both the deflazacort and prednisolone groups. The decrease in L-BMC was significant in the deflazacort group after three, six, and 12 months $(p<0.05)$, but that in the prednisolone group was significant only after 12 months $(p<0.05)$. After three months of treatment, the decrease in L-BMC was significantly greater in the deflazacort group than in the prednisolone group $(p<0.05)$, but after six and 12 months there was no significant difference in bone loss between the two groups. The changes in L-BMC were the same in women and men. For both treatment groups collectively there was a significant difference in L-BMC between the median values for the different measurements (Friedman's test: $\chi^{2}=14 \cdot 16, p=0 \cdot 0027$ ), and a significant decrease in L-BMC during the first year (Page's test: $\left.L^{\star}=-3.43, p=0.0006\right)$ ). The median loss in L-BMC after one year was $6.4 \%$ (95\% CL 1.5 to $10 \cdot 7$ ).

Expressed as percentages, the changes in L-BMC and L-BMD were similar. Expressed in absolute values, the changes in L-BMD compared with baseline values in the deflazacort group were $-0.032 \mathrm{~g} / \mathrm{cm}^{2}(95 \% \mathrm{CL}$ -0.008 to -0.055$)$ at three months $(\mathrm{p}<0.05)$, $-0.039 \mathrm{~g} / \mathrm{cm}^{2}(95 \% \mathrm{CL}-0.025$ to -0.054$)$ at six months $(\mathrm{p}<0.05)$, and $-0.047 \mathrm{~g} / \mathrm{cm}^{2}$ $(95 \% \mathrm{CL}-0.012$ to -0.101$)$ at 12 months $(\mathrm{p}<0.05)$; those in the prednisolone group were $-0.011 \mathrm{~g} / \mathrm{cm}^{2}$ (95\% CL 0.002 to -0.027 ) at three months (NS), $-0.018 \mathrm{~g} / \mathrm{cm}^{2}(95 \% \mathrm{CL}$ 0.033 to -0.059$)$ at six months (NS) and $-0.065 \mathrm{~g} / \mathrm{cm}^{2}(95 \%$ CL 0.014 to -0.090$)$ at 12 months $(p<0.05)$.

For A-BMC there was no significant difference in the bone loss between the deflazacort and prednisolone groups. For both treatment groups collectively there was a statistically significant loss of $1.8 \%$ in A-BMC during the first year (Friedman's test: $\chi^{2}=8 \cdot 880$, $p=0.0309$; Page's test: $L^{\star}=-2.65, p=0.0455$ ).

At six months there was a significant correlation between the changes in L-BMC and the cumulative dose of corticosteroid $(r=0.400, \mathrm{p}<0.05)$ that was not found at three and 12 months $(p>0 \cdot 1)$. There was also a significant correlation between disease activity at six weeks and three months and the changes in L-BMC after six months $(r=0.4048, \mathrm{p}<0.05)$, but not after three or 12 months $(p>0 \cdot 1)$. The 12 patients who had disease activity at six weeks, three months, or both, had significantly lower L-BMC after six months $(p=0.05)$, but not after three or 12 months, compared with the patients who had full remission of symptoms. Nearly all patients were free from symptoms at six and 12 months. There was no correlation between disease activity at six weeks and three months and cumulative steroid dose at three and six months $(p>0 \cdot 1)$.

\section{Discussion}

In the present study we were unable to demonstrate any significant bone sparing effect of deflazacort as compared with prednisolone, finding on the contrary that after three months the bone loss was greater in the deflazacort group. These observations resemble those of Messina et $a l^{9}$ in patients with rheumatoid arthritis, but are in contrast to those of a number of other studies. ${ }^{3}$ Several factors could explain this discrepancy.

First, even though many of the studies were double blind and randomised, a fixed dose ratio of deflazacort $6 \mathrm{mg}$ and prednisolone $5 \mathrm{mg}$ was used, and a fixed number of tablets was assigned for the treatment periods concerned. ${ }^{5} 7910$ This did not automatically result in the two treatment groups being treated with equipotent doses of corticosteroid. The finding of an anti-inflammatory equipotency ratio of 7.5:5 (deflazacort:prednisolone) in polymyalgia patients ${ }^{11}$ suggests that deflazacort may have been given in doses of slightly inferior potency in some of the randomised studies. In our study the dose was fixed in a 6:5 (deflazacort:prednisolone) ratio only for the initial six weeks, and during most of the examination period the dose was reduced to the smallest that was able to keep the symptoms under control. Even though it was necessary to increase the dose of corticosteroid to more than $24 \mathrm{mg} /$ day in four patients in the deflazacort group during the first six weeks, patients treated with deflazacort had significantly more symptoms of polymyalgia after six weeks and three months than patients treated with prednisolone. This suggest that the potency of the dosage in the deflazacort group was reduced during the first six weeks of our treatment procedure and increased only gradually after the period of fixed dosage.

Second, assuming that the bone loss associated with corticosteroids is dose dependent, a difference in side effects between deflazacort and prednisolone would be easier to determine in high dose studies ${ }^{5}$ than in our low dose study. In a randomised study of low dose treatment of rheumatoid arthritis ${ }^{9}$ no difference could be found between the side effects of deflazacort and prednisolone after one year. It is possible that the magnitude of any difference is not great enough for detection in low dose regimens, and therefore the risk of a type 2 error is greater in a low dose than in a high dose study. In our study, had the actual bone loss at 12 months in the deflazacort group been $50 \%$ as great as that in the prednisolone group, it would have been detected with a likelihood of $0 \cdot 68$.

It may be asked why, if patients in the deflazacort group received smaller doses of corticosteroid during the first six weeks to three months of the study, the bone loss in the deflazacort group was significantly greater after three months in our study? This may be because factors other than corticosteroid treatment were of importance for the bone loss. Patients with disease activity at six weeks and three months had a significantly faster decrease in L-BMC than symptom free patients. At six and 12 months, only a few patients had symptoms. In patients undergoing bed rest for backache, an L-BMC loss of $0.9 \%$ per week 
has been shown. ${ }^{12}$ Even though the period of disease before treatment in our patients was short (mean 2.5 months) and in many patients there was a quick clinical response to the treatment, the reduced mobility during the symptomatic period of the disease may have been a significant determinant of the grade of bone loss. This could also explain why the rate of bone loss was greater during the first three months. The clinical implication of this is uncertain, as the weight of the different factors influencing the bone loss (dose of steroids, reduced mobility because of symptoms, and others) is not known.

In patients with polymyalgia rheumatica treated with low dosage corticosteroids, there was a significant decrease in L-BMC of $6.47 \%$ and in A-BMC of $1.80 \%$ during the first year of corticosteroid treatment. The expected physiological loss in L-BMC in this age group is $1 \%$ per year for women, and less for men. ${ }^{13}$

The initial changes in L-BMC occurred remarkably quickly, as there was a significant reduction after only three months of treatment. The rate of loss during the period from three to 12 months seemed to be slower than that during the first three months. This has been described in patients receiving high dose corticosteroid treatment ${ }^{14}$ and in very small groups of patients taking low dose corticosteroid medication. ${ }^{15}$ The mechanism may relate to a new steady state in bone metabolism, or may simply be a manifestation of a dose-response phenomenon, as treatment with corticosteroids is often started with a relatively high dose, which is reduced after few months.

There is no evidence for a strong relation between the loss of bone mass and daily dosage $^{3}$ or cumulative dose $\mathrm{e}^{2}$ of corticosteroids. We found a significant correlation between changes in BMC and cumulative dose of corticosteroids only at six months, not at 12 , and this correlation may have been significant only because multiple comparisons were made. The correlation coefficient was 0.400 (close to that reported by others ${ }^{3}$ ), which implies that only $16 \%$ of the bone loss after six months could be explained by the differences in dosage.

In conclusion, a calcium sparing property of deflazacort compared with prednisolone could not be demonstrated in this study. After low dose corticosteroid treatment during one year, lumbar bone mass was reduced significantly and by more than the expected age related bone loss.

This study was supported financially by the Danish Rheumatism Association, by the Danish Hospital Foundation for Medical Research, Region of Copenhagen, The Faroe Islands and Greenland, and by the Deaconess House Saint Luke's Foundation. Corticosteroid tablets were kindly supplied by Lepetit Research Laboratories, Milan, Italy.

1 Adinoff A D, Hollister J R. Steroid induced fractures and bone loss in patients with asthma. $N$ Engl $f$ Med 1983 ; bone loss in

2 Dykman T R, Gluck O S, Murphy W A, Hahn T J, Hahn B H. Evaluation of factors associated with glucocorticoid-induced osteopenia in patients with rheumatic disease. Arthritis Rheum 1985; 28: 361-8.

3 Reid D M, Kennedy N S J, Smith M A, et al. Bone loss in rheumatoid arthritis and primary generalised osteoarthrosis: effects of corticosteroids, suppressive antirheumatic drugs and calcium supplements. $\mathrm{Br} f$ Rheumatol 1986; 25: 253-9.

4 Sambrook P N, Eisman J A, Champion G D, Yeates M G, Pocock N A, Eberl S. Determinants of axial bone loss in rheumatoid arthritis. Arthritis Rheum 1987; 30: 721-8.

5 Ølgaard K, Storm T, Wowern N V, et al. Glucocorticoidinduced osteoporosis in the lumbar spine, forearm, and mandible of nephrotic patients: a double-blind study on the high-dose, long-term effects of prednisone versus deflazacort. Calcif Tissue Int 1992; 50: 490-7.

6 Sambrook P N, Eisman J A, Yeates M G, Pocock N A Eberl S, Champion G D. Osteoporosis in rheumatoid arthritis: safety of low dose corticosteroids. Ann Rheum Dis 1986; 45: 950-3.

7 Loftus J K, Reeve J, Hesp R, David J, Ansell B M, Woo P M M. Deflazacort in juvenile chronic arthritis. f Rheumatol 1993; 20: 40-2.

8 Bird H A, Esselinck W, Dixon A St J, Mowat A G, Wood P H N. An evaluation of criteria for polymyalgia rheumatica. Ann Rheum Dis 1979; 38: 434-9.

9 Messina O D, Barreira J C, Zanchetta J R, et al. Effect of low doses of deflazacort vs prednisone on bone of low doses of deflazacort vs prednisone on bone mineral content in premenopa

10 Gray R E S, Doherty S M, Galloway J, Coulton L, de Broe $M$, Kanis J A. A double-blind study of deflazacort and prednisolone in patients with chronic inflammatory disorders. Arthritis Rheum 1991; 34: 287-95.

11 Lund B, Egsmose C, Jørgensen S, Krogsgaard M R Establishment of the relative antiinflammatory potency of deflazacort and prednisone in polymyalgia rheumatica. Calcif Tissue Int 1987; 41: 316-20.

12 Krølner B, Toft B. Vertebral bone loss: an unheeded side effect of therapeutic bed rest. Clin Sci 1983; 64: 537-40.

13 Pacifici R, Susman N, Carr P L, Birge S J, Avioli L V. Single and dual energy tomographic analysis of spinal trabecular bone: a comparative study in normal and osteoporotic bone: a comparative study in normal and osteopor

14 Thamsborg G, Storm T L, Sørensen O H. Serial changes in forearm and lumbar bone mineral content (BMC) during treatment with glucocorticoids in patients with during treatment with glucocorticoids in patients with giant

15 Gennari C, Imbimbo B. Effects of prednisone and deflazacort on vertebral bone mass. Calcif Tissue Int 1985; 37: 592-3. 